\title{
Reflective Approaches in Medical Education. Implications on Medical imaging.
}

\author{
Raja Farahhana Raja Azhar \\ International Islamic University Malaysia, rajafarah.azhar@yahoo.com \\ Haji Mohamed Nadzri Mohd Yusoff \\ Universiti Teknologi Mara, Malaysia, nadzy65uitm@puncakalam.uitm.edu.my \\ Zainul Ibrahim Zainuddin Dr. \\ International Islamic University Malaysia, izainul@gmail.com
}

Follow this and additional works at: https://nsuworks.nova.edu/ijahsp

Part of the Education Commons, and the Medicine and Health Sciences Commons

This Manuscript has supplementary content. View the full record on NSUWorks here: https://nsuworks.nova.edu/ijahsp/vol16/iss2/8

\section{Recommended Citation}

Raja Azhar R, Mohd Yusoff H, Zainuddin Z. Reflective Approaches in Medical Education. Implications on Medical imaging.. The Internet Journal of Allied Health Sciences and Practice. 2018 Jan 01;16(2), Article 8.

This Manuscript is brought to you for free and open access by the College of Health Care Sciences at NSUWorks. It has been accepted for inclusion in Internet Journal of Allied Health Sciences and Practice by an authorized editor of NSUWorks. For more information, please contact nsuworks@nova.edu. 


\section{Reflective Approaches in Medical Education. Implications on Medical imaging.}

\section{Abstract \\ Abstract}

Purpose: This paper reviewed literature regarding the utility and direction of reflective approaches in Medical imaging education.

Methods: The Scopus database was accessed. The word "Reflective" was used as the main search term to look for the relevant literature. The inclusion criteria used in this study comprised of those papers published in English between the years 2006 to 2016, indexed in Scopus database, and limited to those discussing the topic on reflective approaches in medical education. Published papers that have the main search terms in the articles' title only were tabulated. The data were then filtered using other Reflective related terms. Thematic analysis was done.

Results: Two hundred and four articles were identified to have one or more search terms in the articles' titles only. Studying the data using other reflective related terms revealed that the term "Reflective Writing" contributed the highest frequency, followed by "Reflective Journal" and "Reflective Learning". Twentyfour studies evaluated students' reflective approaches in assessing and improving the domain of professionalism in Medical sciences. Twenty-two studies showed the researchers utilized various types of reflective approaches for evidence of students learning skills. Other studies noted the efficacy of different types of reflective learning in the domains of attitude, teamwork, empathy, learning skill, competencies, clinical skill and patient care. Pertinent to Medical imaging education area, only two studies were found; one reported the promotion of reflective learning while the other touched on the portfolio.

Conclusion: This review, based on Scopus database, depicts the educational approaches that made use of the concept of reflection. They are used to facilitate the learning and assessment in various medical disciplines. There is a dearth of articles that address reflective approaches in relation to Medical imaging education. Much work is required to understand how reflective approaches can be used to effectively assess the students' performances in various domains in Medical imaging education.

\section{Author Bio(s)}

Raja Farahhana RA, B. Sc is a Masters student in International Islamic University Malaysia. She is working as a tutor in the department of Medical Imaging, Vision College, Malaysia. She has a special interest in Medical imaging education.

Nadzri Mohamed MY, M.Sc, B.Sc is a senior lecturer in the Medical Imaging department, faculty of Allied Health Sciences, University Teknology Mara. He is currently involved in promoting Outcome-Based Education (OBE) under the Malaysian Qualification Agency. He has been teaching Medical imaging for 18 years.

Zainul I Zainuddin, Ph.D, M.Sc, B.Sc is an Assistant Professor In Medical Imaging at the Department of Diagnostic Imaging and Radiotherapy, Kulliyyah of Allied Health Sciences, International Islamic University Malaysia. He has been teaching Medical imaging for 16 years.

\section{Acknowledgements}

I would like to acknowledge the contributions of Dr.Zainul Ibrahim Zainuddin and Mr. Mohamed NadzriMohdYusoff who jointly supervised this work. 


\title{
IJAHSP \\ The Internet Joưnal of Allied Health Sciences and Practice
}

Dedicated to allied health professional practice and education

Vol. 16 No. 2 ISSN 1540-580X

\section{Reflective Approaches in Medical Education. Implications for Medical Imaging}

\author{
Raja Farahhana RA, B. Sc ${ }^{1}$ \\ Nadzri Mohamed MYM.Sc, B.Sc ${ }^{2}$ \\ Zainul I Zainuddin, Ph.D, M.Sc, B.Sc ${ }^{1}$ \\ 1. International Islamic University Malaysia \\ 2. Universiti Teknologi Mara, Malaysia
}

Malaysia

\begin{abstract}
Purpose: The literature regarding the utility and direction of reflective approaches in medical imaging education was reviewed. Methods: The Scopus database was accessed. The word reflective was used as the main search term to look for the relevant literature. The inclusion criteria used in this study included those papers published in English between the years 2006 to 2016, indexed in Scopus database, and limited to articles about reflective approaches in medical education. Published papers that had the main search terms in the articles' title only were tabulated. The data were then filtered using other reflective-related terms. A thematic analysis was done. Results: Two hundred and four articles were identified to have one or more search terms in the articles' titles only. Studying the data using other reflective-related terms showed that the term reflective writing had the highest frequency, followed by reflective journal and reflective learning. There were 24 studies in which students' reflective approaches were evaluated for assessing and improving the domain of professionalism in medical sciences. Twenty-two studies showed that the researchers utilized various types of reflective approaches for evidence of students' learning skills. In other studies, the efficacy of different types of reflective learning in the domains of attitude, teamwork, empathy, learning skills, competencies, clinical skills, and patient care were explored. Pertinent to the medical imaging education area, only two studies were found. The promotion of reflective learning was reported in one, and the use of the portfolio was mentioned in the other. Conclusion: This review, based on Scopus database, demonstrated the educational approaches that were used for the concept of reflection. Educational approaches were used to facilitate the learning and assessment in various medical disciplines. There was a dearth of articles in which reflective approaches were addressed in relation to medical imaging education. Much work is required to understand how reflective approaches can be used to effectively assess the students' performances in various domains in medical imaging education.
\end{abstract}

\section{INTRODUCTION}

Reflection in education can be referred to as learning from experience that requires students to think deeply and critically in the situation they were involved and relate those situations to the theoretical knowledge. This concept is used widely in many profession-based programs as the implementation of reflective learning is essential to produce graduates trained with professional roles. ${ }^{1}$ The discussion pertaining to the concept of reflection used in education is initiated with the definition of reflection as given by Dewey (1910): " ... active, persistent and careful consideration of any belief or supposed form of knowledge in the light of the grounds that support it and the further conclusion to which it tends. "2 Rogers emphasized that reflection is "a meaning-making process that moves a learner from one experience into the next with deeper understanding of its relationships with and connections to other experiences and ideas," involving a complex, rigorous, intellectual and emotional enterprise that takes time to be appreciated. ${ }^{3}$ Reflection is recognized as a process of integration between theory and real situations or experiences, which a person should be able to link and blend both together. ${ }^{3}$ This linkage of theory and practice needs thoughtful, critical, and deep thinking to achieve reflection.

Another definition of reflection made through the introduction of the term reflective practice is "reflective practice involves thoughtfully considering one's own experiences in applying knowledge to practice while being coached by professionals in the

(c) The Internet Journal of Allied Health Sciences and Practice, 2018 
discipline. ${ }^{\prime 4}$ This definition is further expressed as the process of critical thinking when a person needs to use the conscious mind to ponder, analyze, evaluate, judge, and criticize a particular issue. ${ }^{5}$ Reflection was taken as an action of an individual to face certain situations or conditions with full mindfulness of thinking and provide better response and achievement in the future. ${ }^{6}$ Thus, there are broad definitions for the term reflection. These broad definitions can be used to relate the application of reflection within their individual contextual meanings.

Dewey has highlighted four major principles of reflection. ${ }^{2}$ Reflection is used to facilitate the search of meaningful understanding through the application of a systematic, rigorous, and disciplined way of thinking. Reflection needs to happen in a community, which requires attitudes that value the personal and intellectual growth. Based on Dewey's work, Rodgers outlines reflection in six phases: (1) an experience, (2) spontaneous interpretation of the experience, (3) naming the problems or questions that arises out of the experience, (4) generating possible explanations for the problems or questions, (5) ramifying the explanations into hypotheses, and (6) experimenting or testing the selected hypotheses. ${ }^{3}$ At the initial stage of reflective thought, an experience is needed for a reflective thinker to formulate a theory. After an experience, a spontaneous clarification of the experience follows. In this case, Dewey noted that once a reflective thinker has an experience, he or she will "perceive" a fact. For the third phase, Dewey labeled it as "thought intellectualization" or "locating the problem." The process involved in this phase does not occur by chance. Rather, it demands a disciplined approach when an individual needs to continually ground his or her thinking. The fourth phase involves analysis. This phase involves the reflective thinker to formulate the hypotheses based on various sources, previous experiences, books, and people. Phase five is a more intense and focused version of phase four in which an intellectual reviews a series of problems or questions, which provides a platform of reason and understanding of the issues and will lead a reflective thinker to go to the next phase. Finally, the last step of the reflection phases is to investigate the hypotheses. As noted by Dewey (1910), reflection must include an action. ${ }^{2}$ This final phase of reflection is the one that offers the possibility of a resolution to the problem.

The steps involved in a reflection process can be divided into four stages. ${ }^{7}$ First is the description process when a student needs to think about the actions that occurred in an event. The second stage is the analysis and interpretation process. This stage involves the question of why the event happened. Third is the meaning and application process. This process requires students to verify the justification of why that event is significant to reflect upon. The last step encompasses the implication process. This step shows whether reflection has taken place and how the students provide the solution to the event that arose.

Dewey also proposed eight steps in reflective thinking. ${ }^{2}$ The steps start with problem definition followed by problem analysis, criteria selection, information analysis, proposed solution, selected solutions, implemented solutions, and feedback of the solutions. All these steps need to be utilized in reflective thinking to assure coverage of a defined problem area. In the learning process, the integration of self-reflection with the past and future experiences are needed in order to produce reflective practitioners. ${ }^{8}$ In this case, it was emphasized that reflection is useful in students' learning activities because it shows the concept of the affective domain, which is difficult to sense in the various learning activities. It can be concluded that the steps proposed by the various authors were meant to facilitate for reflection to be manifested in the students' thinking and learning.

The role of reflection in education has been able to generate positive roles in fostering students' reflective thinking, critical thinking, and professionalism. ${ }^{9}$ The concept of reflection is acknowledged in the education system as a method for developing deep learning and using various assignments given to students. ${ }^{10}$ Reflective approaches are used for students to reflect on the knowledge they learned about theory and to apply those into practice. ${ }^{2}$ Reflective writing assignments in medical education were used to direct students' attention to foster their professional development and engage multiple orientations. ${ }^{11}$ Collectively, the authors emphasized that reflective approaches are widely used to increase emphatic interaction with patients, improve communication skills, and spirituality.

Generally, student development in the learning process is guided by the three domains of learning or learning taxonomies, which are the cognitive, psychomotor, and affective domains. The Malaysian Qualification Agency (MQA) used these domains of learning to define the minimum performance achievement upon completion of a course or a program. ${ }^{12}$ Discussions pertinent to the domains of learning should not omit the assessment method. The correct assessment methods are important to evaluate the students' performance related to those domains.

Numerous forms of reflective approaches have been developed and introduced as tools in assessing students' performances in the various aspects of teaching and learning. Among others, those assessments related to the soft skills of thinking, scientific skills, communication skills, social skills, professionalism, and leadership skills. The Malaysian Qualification Agency clarified that multiple assessment methods should be adopted in measuring the attainment of learning outcomes, which include the diverse attributes to

(C) The Internet Journal of Allied Health Sciences and Practice, 2018 
be measured. ${ }^{12}$ However, the use of the reflective approaches that include written examinations to assess soft skills are subjective and complex..$^{13}$ Thus, appropriate methods need to be determined to measure those skills for students' performance.

There are various terms that relate to reflective approaches used within the context of education. They include reflective learning, reflective writing, reflective journal, reflective portfolio, reflective exercise, reflective model, and reflective tool. Generally, these reflective approaches involve the concept of reflection. Although the assessment tool to measure interpersonal skills, such as professionalism, teamwork, and proficiency in medical education, is hard to outline. Reflective approaches could be beneficial in evaluation of those domains as documented in the literature..$^{14}$ In this case, there are educators who believe that engaging medical students with reflective writing is one of the means in promoting the medical aspect of professionalism. ${ }^{15}$ Reflective writing has the potential to assist professional program students to assimilate the relationship between personal experiences and professional values. ${ }^{16}$ The impact of reflective writing on empathy among students was measured by Chen and Forbes and was found to support the assimilation of personal experiences and professional values. They found that reflective writing contributes substantial change in medical students' empathy, which indicates that the use of reflective writing in medical education can enhance the social skills of the students with patients. ${ }^{17}$ Thus, it was felt that reflective approaches could be relevant to medical imaging education in measuring and evaluating students' cognitive, affective, and psychomotor domains in those individual theoretical domains of the discipline.

In spite of the importance of reflective approaches mentioned above, there seems to be little evidence to suggest reflective approaches in the various domains of medical imaging education. Without the appropriate methods of assessment, the evidence of psychomotor and affective competencies in technological skills, patient care, clinical skills, professionalism, social skills, safety, economy, quality, and meeting customer satisfaction among the medical imaging graduates will be difficult to assess. It can be highlighted here that some of the domains related to medical imaging education can be evaluated with the use of reflective approaches used in other disciplines in medical education. The characteristics of the soft skills in other disciplines of medicine that had been evaluated using reflective approaches could be similar to those in medical imaging education.

The objective of this paper was to identify the direction of recent works in reflective approaches in medical education and, in particular, medical imaging education. The focus of this review was on the identification of various types of reflective approaches and their usage in assessing the theoretical domains in the medical education and medical imaging education scenarios. The research questions that guided this review were the following:

1. What are the types of reflective approaches used in medical education within the last 10 years?

2. What are the lessons learned from the use of those reflective approaches in the teaching and learning within the medical education scenario?

3. What are the types of reflective approaches used in medical imaging education?

4. How effective have reflective approaches been used in assessing the theoretical domains in medical imaging education?

It is to be reiterated at this junction that for the purpose of this paper the terms radiography and medical imaging are used interchangeably.

\section{METHODS}

With the search strategy, published studies about reflective approaches in medical education were sought. This study involved the Scopus database. Scopus is an important database in literature search studies, for it is said to provide $100 \%$ Medline coverage. Thus, a full coverage of literature related to the field of medical imaging was secured.18 The inclusion criteria used in this study included published papers indexed in the Scopus database. Only papers published in English, publications between the years 2006 to 2016, and articles that included the topic of reflective approaches in medical education were examined.

In the first phase of the search, the Scopus database (,http://www.scopus.com/) was accessed. The researcher used the word reflective as the main search term. Using the search platform, the publication option from "2006-2016" and "All Documents" were entered. The search limited the search term to appear only in "Title, Abstract, and Keywords." The total number of publications identified in the search was recorded.

Then the "filtering" function was utilized in which only articles published in English were chosen. Filtering the results further, the search was then limited to six areas of studies: medicine, nursing, health professions, social sciences, multidiscipline, and undefined. The number of articles was then recorded. The identified articles were then exported for further analysis using the comma separated values (CSV) function, which tabulated the resultant data into an Excel file. The data in the exported Excel file relevant to this study included the name of authors, the title of articles, year of publication, journal title, abstract, and keywords.

(c) The Internet Journal of Allied Health Sciences and Practice, 2018 
From the Excel file, the data were filtered for the number, types, and frequencies of articles that had the reflective-related terms. The reflective-related terms indicate the reflective methods used in the current education system. Terms that included reflective writing, reflective learning, reflective journal, reflective tool, reflective portfolio, reflective exercise, and reflective model were filtered with the use of the source's title column. The results were tabulated.

Descriptive analyses and thematic analyses of the above results were tabulated. These analyses were calculated to present an overall picture pertaining to selected disciplines in medical education and later to compare with medical imaging education.

Results

The initial search identified 71,548 articles in various subject areas that had the search term reflective in the title, abstract, or keywords. The total number of articles was then filtered to subject areas related to medicine: medicine, nursing, social sciences, health profession, multidiscipline, and undefined, which totaled 18,676 articles. The breakdown within each subject area is given in Table 1.

\section{RESULTS}

The initial search identified 71,548 articles in various subject areas that had the search term reflective in the title, abstract, or keywords. The total number of articles was then filtered to subject areas related to medicine: medicine, nursing, social sciences, health profession, multidiscipline, and undefined, which totaled 18,676 articles. The breakdown within each subject area is given in Table 1.

Table 1. The Breakdown of Articles According to the Chosen Subject Areas

\begin{tabular}{|l|c|l|c|}
\hline \multicolumn{1}{|c|}{ Subject Areas } & Number of Articles & \multicolumn{1}{c|}{ Subject Areas } & Number of Articles \\
\hline Social Sciences & 9395 & Health Professions & 693 \\
\hline Medicine & 6801 & Multidisciplinary & 217 \\
\hline Nursing & 1549 & Undefined & 21 \\
\hline Total & & & 18,676 \\
\hline
\end{tabular}

An increasing trend in publications with reflective terms was observed in publications related to medicine from 2006 to 2015 (Figure 1). The increasing trend indicates the awareness concerning the use of the concept of reflection in medical education. In 2016, a decrease in the number of articles with reflective terms is seen, which can be attributed to the fact that this study was conducted in October 2016. Thus, the exact number of articles with reflective terms until the end of 2016 was not obtained.

Figure 1. The Trend in Articles Indexed in Scopus with Reflective Terms from 2006 to 2016 Limited to Subject Areas Related to Table 1

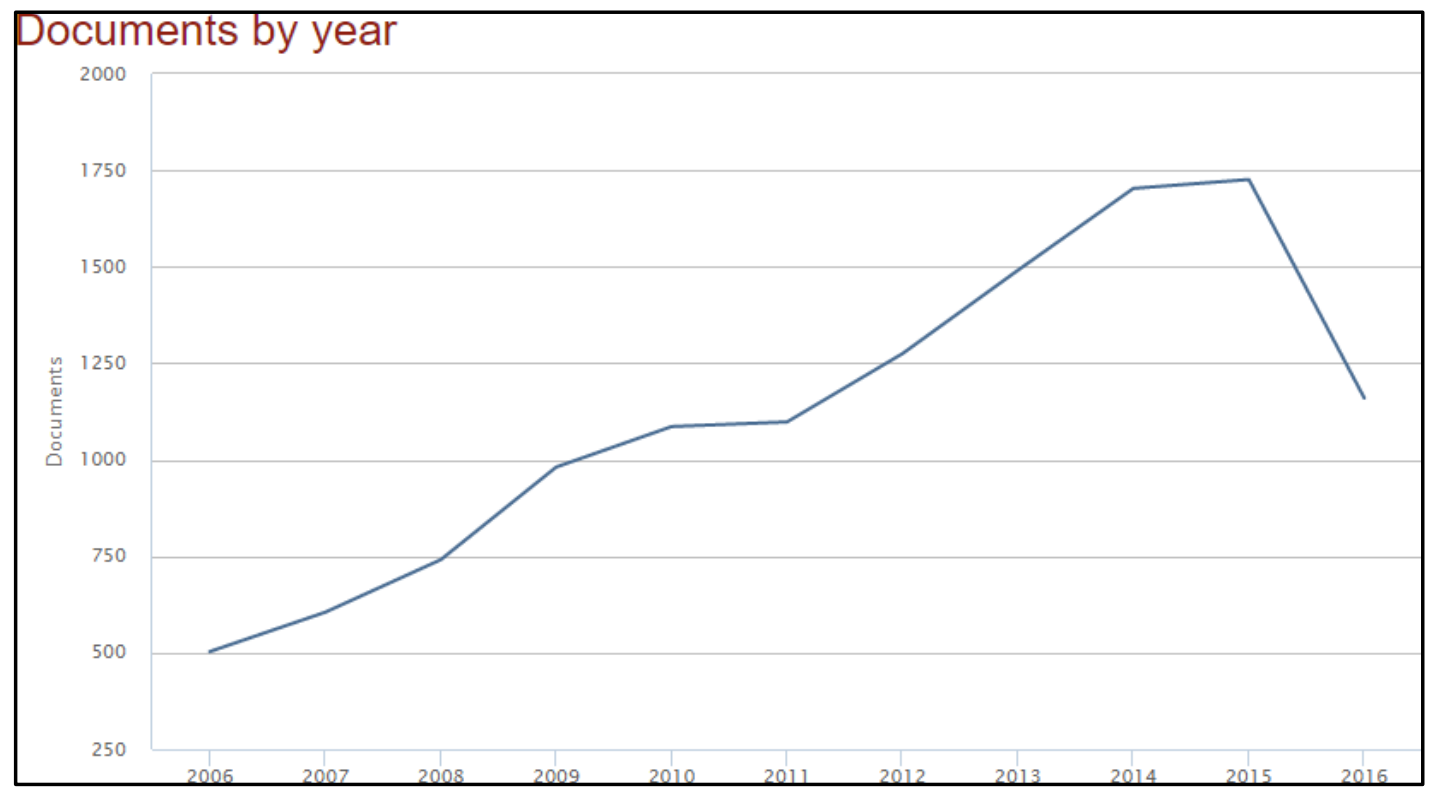

(c) The Internet Journal of Allied Health Sciences and Practice, 2018 
From the total number of 18,676 articles, only 204 articles had one or more reflective-related terms of reflective writing, reflective learning, reflective journal, reflective tool, reflective portfolio, reflective exercise, and reflective model in the titles of the articles. The term reflective writing had the highest frequency in the article titles, followed by reflective journal and reflective learning. It is to be reiterated at this point that for this study, the identified reflective-related terms can represent the approaches used in medical education, including those in medical imaging education. Limiting the search terms to the title only denoted the emphasis or importance of those terms as the core discussion within the retrieved articles. The themes and frequencies for which the reflectiverelated terms appear are given in Table 2.

Table 2. The Frequency of the Various Reflective-Related Terms in the Articles' Titles

\begin{tabular}{|l|c|}
\hline \multicolumn{1}{|c|}{ TERMS } & Frequency in Article Titles \\
\hline Reflective Writing & 61 \\
\hline Reflective Journal & 57 \\
\hline Reflective Learning & 48 \\
\hline Reflective Model & 11 \\
\hline Reflective Portfolio & 10 \\
\hline Reflective Tool & 9 \\
\hline Reflective Exercise & 8 \\
\hline Total & 204 \\
\hline
\end{tabular}

From the list of 204 articles titles, the data were filtered to identify articles in which reflective approaches in medical education were discussed. There were 113 articles found. A thematic analysis was performed. The scope that each article highlighted for the 113 articles is given in Table 3 .

Table 3. Thematic Analyses of Articles' Title

\begin{tabular}{|l|c|}
\hline Thematic Analyses & Frequency \\
\hline $\begin{array}{l}\text { Evaluation of reflective approaches in assessing theoretical domains in medical } \\
\text { education }\end{array}$ & 67 \\
\hline Implementation of reflective approach in medical education & 16 \\
\hline Perception on reflective approaches: Students, Faculty, Teachers & 7 \\
\hline Effectiveness of reflective approaches in medical education & 4 \\
\hline Models of reflective approaches & 3 \\
\hline The concept of reflective approaches & 2 \\
\hline Development of reflective approaches & 113 \\
\hline Total & \\
\hline
\end{tabular}

Table 3 shows the core areas that the researchers highlighted in their work. Generally, the articles about reflective approaches thematically indicate that the works were concentrated mainly in assessing the reflective approaches in the domains of medical education, which suggests the use of reflective approaches as assessment tools in medical education.

The 113 articles were then subjected to thematic analysis to determine the subdomains in medical education. The frequencies of the subdomains that each article highlighted are presented in Table 4. 
Table 4. The Subdomains Related to the Articles

\begin{tabular}{|c|c|}
\hline Subdomains of Learning & Frequency \\
\hline Professionalism & 24 \\
\hline Learning Skill & 22 \\
\hline Reflective Thinking & 19 \\
\hline Critical Thinking & 11 \\
\hline Clinical Skill & 10 \\
\hline Empathy & 4 \\
\hline Experience & 4 \\
\hline Competency & 4 \\
\hline Attitude & 3 \\
\hline Patient Care & 3 \\
\hline Social Skill & 2 \\
\hline Cognitive Skill & 2 \\
\hline Spiritual Care & 2 \\
\hline Ethics & 1 \\
\hline Teamwork & 1 \\
\hline Technology & 1 \\
\hline Palliative Care & 1 \\
\hline Interpersonal skill & 1 \\
\hline Total & 115 \\
\hline
\end{tabular}

Table 4 illustrates the subdomains that were highlighted by each article. Although the total number of articles found in medical education area was 113 , the total number given above is 115 , which is because there were 2 articles that addressed 2 subdomains. It can be seen that the subdomain of professionalism received the highest attention by various researchers in their studies, which could be attributed to the fact that professionalism is a very important area in the medical field. The dearth of studies in the other subdomain involving experience, ethics, teamwork, empathy, spiritual care, and patient care indicates the directions for future studies. A positive interpretation of the above findings is that reflective approaches addressing the areas under professionalism, learning skills, reflective thinking, critical thinking, and clinical skills when seen within their own individual contexts are similar areas that are given in medical imaging education. The adaptability of those studies to medical imaging education can be positive.

From the data presented in the Excel file, there were only 2 studies related to medical imaging education that have reflective terms in the titles. Hamilton and Druva concentrated on the use of reflective learning in medical imaging education. ${ }^{19}$ Hamilton and Druva suggested that reflective learning can be enhanced by engaging the students with writing tasks. For medical imaging applications, Hamilton and Druva emphasized that students need to reflect on any episodes and situations that happened during their clinical practice. They reported about an intervention in student reflective writing tasks to address issues that are based on clinical experiences. In addition, lecturers' perceptions about the use of reflective writing indicated students are still lacking in making an observation and expressing their views and opinions. Hamilton and Druva also found potential issues in reflective learning, which included the appropriate methods to instill the critical thinking and to preserve positive attitudes among students during clinical placements..$^{19}$

Mubuuke et al developed a descriptive cross-sectional study involving both radiography students and teachers in a college of health science. ${ }^{20}$ They evaluated the effectiveness of a student portfolio as a tool for showing evidence of learning. They found the application of a general log book only is not sufficient to make the students reflect unless they are involved with the portfolio. Students and teachers did not know about the portfolio due to the confusion between a portfolio and a log book. They devised and evaluated a practical portfolio assessment strategy. Overall, Mubuuke et al suggested that students tend to reflect on their learning by using a portfolio compared with a log book only. Thus, the content of portfolio should be selected carefully, and the assessment of a portfolio should be formulated to make a portfolio as a tool of reflection in medical imaging education. ${ }^{20}$ 
Google Scholar was also used to search for articles with reflective terms in medical imaging education after the Scopus study. The articles were extracted using various reflective terms and medical imaging in the titles. In a review, Hall and Davist recognized the growth of the concept of reflective practice in the professions of allied health sciences and medicine. ${ }^{21}$ Noting that the concept was intensely discussed by the nursing professions, they encouraged other professionals, including radiographers, to grasp the concept of reflection more readily. Hall and Davist opined that the use of reflection could enable the professionals to meet challenges in future practices ${ }^{21}$ Our study did not unearth any other literature that represented follow-up discussions pertaining to the concept following the article by Hall and Davist, published in 1999.

In 2008, Baird rekindled the interest in the concept of reflection in medical imaging education. ${ }^{22}$ The study was conducted at Monash University, Australia, which involved fourth-year bachelor of radiography and medical imaging students, and demonstrated the perceptions and feedback of students and supervisors regarding the implementation of a reflection concept in curricula toward the development of a reflective radiographer. Baird found that both students and supervisors supported and accept the program and its mission and vision. However, Baird felt that educators particularly will experience many challenges and constraints in presenting the reflection concept in the curriculum. ${ }^{22}$ Chelliah and Arumugam assessed the stage of reflection and its relationship with clinical competency assessments, which caused them to believe that reflection can promote the clinical competencies among the students. ${ }^{23}$

The lack of literature relating the concept of reflection to medical imaging education is hereby acknowledged. It would then be practical to review and make good of research done in other fields of medicine and align them to the teaching and learning in medical imaging education. The following discussion makes benefit of those general works in reflective approaches in medical education, culminating with applications in medical imaging education.

\section{DISCUSSION}

\section{Reflective Approaches in Medical Education}

The scarcity of literature that relates the concept of reflection to medical imaging education raises questions pertaining to the awareness of a concept that has been shown to be valuable in assessing the domains of learning in other medically related disciplines. The ensuing discussion was used to align reflective approaches used in the other disciplines in the field of medicine to medical imaging education.

The three main reflective approaches that were identified from the literature search are reflective writing, reflective journal, and reflective learning. These approaches are discussed in terms of their meaning, use in medical education, and their use in the domains of medical imaging education.

\section{Uses of Reflective Writing}

Fink stated, "Reflective writing ... focuses on the writer's learning experience itself and attempts to identify the significance and meaning of a given learning experience, primarily for the writer."16 Through writing, the reflection, clarification of thoughts, and organization of knowledge can be achieved by students. ${ }^{24}$ Reflective writing should be based on personal experiences and fused with logical, reflective, hypothetical, creative, and imaginative thinking. ${ }^{10}$ Collectively, Chinniah and Nalliah further claimed that the elements of descriptive, explanatory, and expressive should be added in reflective writing to make it more beneficial. Thus, reflective writing is an avenue in which writers can enhance their curiosity by producing more questions than answers. Thus, reflective writing can be described as a process of learning, which needs students to act, to think critically, to analyze the idea, and to put all the process in writing.

The style of reflective writing might be different from academic writing because the process of writing reflectively comes from the inner self of the students after they have thought reflectively. There are four criteria in reflective writing. Those include reporting and responding to a critical issue or experience, relating the issue to students' knowledge in their field, reasoning about the causes and effects of the issue, and reconstructing the thinking to provide solution to the issue. ${ }^{25}$

Reflective writing is used extensively in the clinical setting in many health sciences educational programs.19 Students' learning outcome and critical thinking can be evaluated by means of reflective writing. ${ }^{24} \mathrm{It}$ is believed that besides other kinds of assignments in education system, reflective writing could be used for both the integration of theory and practice and enhancement of the reflective thinking among students. ${ }^{16}$ The standard assignment limits students' ability to develop insights into their own biases. The common types of assignments that have been used as reflective writing include portfolios, learning journals, log books, case summaries, Web-based learning, and peer review. ${ }^{10}$ Chinniah and Nalliah added that students' understanding of a given case plus the analytical skill could be evaluated through their writing style regardless of the type of reflective writing. ${ }^{10}$ Hence, any deficits or gaps in their knowledge can be corrected through the teacher's feedback. In addition, students think about the situation of other

(C) The Internet Journal of Allied Health Sciences and Practice, 2018 
people through writing and could contemplate their own reactions in relation to those situations by writing reflectively. ${ }^{15}$ Shapiro et al concluded that students are able to become more confident in exploring the voices of patients, patients' family, and others. ${ }^{15}$

In medical education, professionalism is identified as a domain of competency, which needs to merge the knowledge, skill, and attitude for professional practice. ${ }^{26}$ Black and Plowright evaluated the views of pharmacists about reflection. ${ }^{27}$ They provided a picture about reflection and its effect toward professional development among postgraduate pharmacy students. From the focused group discussion and individual interviews, the students perceived that reflection can enhance their professional development in terms of patient care and their interaction with other health professionals. In addition, the students also seem to be aware of the depth and level of reflection because of the level of their education. ${ }^{27}$ Braun et al examined whether reflective writing can be used to assess the professionalism competencies among medical students and found that the content of reflective writing is suggestive of the students being able to address the domain of professionalism upon two competencies, which are ability to display selfawareness of performance and awareness of one's own perspectives and bias. ${ }^{28}$

In nursing education, reflective writing is commonly used in the clinical process to develop students' thinking skills into critical thinking. ${ }^{29}$ Structured and systematic reflective writing is necessary to effectively assess students' critical thinking. A structured model of reflection is believed to encourage the students to think and with further depth. Baker's four-step model and John's revision of Carper's patterns have been used as a model of reflection to guide the students for structured reflective writing, which could enhance the students' understanding of the process of reflection itself and increase their ability to provide critical ideas in their writing. 29

\section{Uses of a Reflective Journal}

A reflective journal is defined as "A collection of notes, observations, thoughts and other relevant materials that were built up over a period of time and usually accompany a period of study, a placement experience or fieldwork." ${ }^{30} \mathrm{~A}$ reflective journal has been used as a means of encouraging the process of critical reflection among students. ${ }^{31}$ On that note, the reflective journal may improve students' clinical skills within the concept of self-directed learning. ${ }^{32}$

Recently, researchers have suggested that engaging students in reflective journaling can give positive effects in their learning, and the domain of critical thinking is improved. 33,34 The use of the reflective journal has been accepted as a teaching strategy whereby students' feelings and observations during their practice is written without any format of writing style. This style ensures the flexibility and openness in writing thus, reflection can be achieved. ${ }^{32}$ The objective of the reflective journal is to develop reflective thinking skills from writing and experiences so that the learning ability can be enhanced.

Nursing students indicated that reflective journal improves their reflective thinking skills. The reflective journal is used as an assessment tool in clinical practice to enhance the stage of development and experience of the students in both knowledge and clinical practice. ${ }^{35}$ Nurses are required to have engaged in critical thinking, clinical decision making, and critical evaluation to provide good service in their working environment. Critical thinking is not a simple process, and it takes time. ${ }^{34}$ Among those drawbacks, Cottrell believed that reflective journaling is one of the types of reflective writing that can be utilized to develop soft skills in nursing education. When nurses are trained in critical thinking through reflective journaling, one of the positive effects is positive patient outcomes.

Lasater and Nielsen used reflective journaling during radiotherapy students' clinical placement and found the concept of reflection led to the formulation of the Guide for Reflection based on Tanner's clinical judgment model.36 From this model, the authors then produced the Lasater clinical judgment rubric to assess the progression of clinical judgment. This model is used to provide students with information regarding the process of the clinical thinking. Lasater and Nielsen concluded that reflective journaling could enhance students' clinical skills only when the students are involved with guided reflections. Reflective journaling was supported by Findlay et al who evaluated radiation therapy students at the University of Newcastle. They suggested that students need to be guided with the style of reflective writing in order to facilitate reflective thinking. ${ }^{37}$ They developed the intervention tool, the Newcastle Reflective Analysis Tool (NRAT), to foster students' reflective writing ability.

Researchers who focused on the domain of critical thinking, learning skills, and clinical skills in nursing education used a structured journal that was based on the concept of reflection in order to provide a depth of knowledge and understanding during clinical practice. ${ }^{38,39}$ Bussard identified eight themes in the nursing students' reflective journal. ${ }^{39}$ The themes included expectations about the patient; recognition of a focused assessment; interpretation of medications, laboratory data, and diagnostics; communication with the patient; collaboration and inter-professionalism; prioritizing interventions; skillfulness with interventions; and incorporation of skills and information into real-patient situations. The findings from these studies have affirmed the correlation of reflective journaling with the academic success in nursing clinical area. McMillan-Coddington evaluated the efficacy of journal writing in

(C) The Internet Journal of Allied Health Sciences and Practice, 2018 
educating nursing students in the domain of patient care, suggesting that students tend to learn how to provide responsible care for patients, incorporating a code of ethics, and empathize with patients. ${ }^{40}$

Because reflective writing and reflective journaling share some basic characteristics, it is conducive for the terms to be used interchangeably, the distinction being reflective journals are based on specific experiences over a period of time.

\section{Reflective Learning}

Both reflective writing and reflective journaling are methods towards achieving reflective learning. Boyd and Fales mentioned that "Reflective learning is the process of internally examining and exploring an issue of concern, triggered by an experience, which creates and clarifies meaning in terms of the self, and which results in a changed conceptual perspective." ${ }^{41}$ Reflective learning is an activity used in pedagogical methodology, and its usage is not limited to the writing process only. Reflective learning includes a range of activities: self-review, peer review, and reflective writing. Thus, it is suggested that the students should be introduced to the concept of reflective learning before they are involved in its associated activities, particularly in reflective writing. Digital storytelling, peer feedback, and blogging are among the learning activities that involve the reflection concept, thus those activities can be classified as reflective learning. The various methods of reflective learning could make the learning process become creative and valuable in extracting certain skills from students. ${ }^{42}$

\section{Applying Reflective Approaches in the Domains of Medical Imaging Education}

The above discussion shows that most of the reflective approaches in medical education were focused on the domains of critical thinking and learning skills among students. Critical thinking, clinical decision making, and critical reflection are among the skills that are also applicable to medical imaging education within the scope of the discipline. The domains of patient care, use of technology, procedural considerations, technical knowledge, professionalism, safety, quality, and customer satisfaction could be assessed through the use of the various reflective approaches above for the purpose of reflective learning. Reflection has been shown to enhance professional development in terms of patient care and professional interaction between health professionals.

The common type of assignments and assessments that have been used as reflective writing include portfolios, learning journals, log books, case summaries, Web-based learning, and peer review. Relating to the situation of other people through writing, students could contemplate their own reactions in relation to those situations by writing reflectively and addressing the domain of professionalism, which is involved in those situations. It is important to note that the expected elements of professionalism in the medical disciplines are relatively the same within the context of expected professional attributes, which are specific to the given discipline.

Accountability, positive communication, empathy, trustworthiness, consideration, respecting others, personal appearances, ensuring privacy and confidentiality, safe practice, limiting harm, self-reflection, and professional development are some of the professional traits expected from medical imaging practitioners. Medical imaging educators can relate the findings of studies in other disciplines in order to integrate the use of reflective writing into these domains of medical imaging professionalism.

A common feature in medical education is the development of critical thinking. This particular ability is also important in medical imaging education. Differences in patient characteristics, imaging technologies, procedures, safety considerations, and image quality are domains that are interconnected with each other in any given radiological examination. The concept of individual

tailoring of radiological examination requires that the thinking ability for no two patients is alike. The use of reflective writing could unearth the analytical skill that is needed in the conduct of the examinations.

The reflective journal, which is characterized by accumulation of experience over time, could be used to develop the reflective thinking skills from writing and experiences so that learning ability can be enhanced. Developing and enhancing critical thinking and soft skills that require time can be seen within the positive outcomes as depicted in the discussions above. It can be highlighted that most of those domains involve the affective domain of learning, which include assessing students' performance in the clinical area in which they can reflect upon specific instances with a single patient, thus using reflective writing or determining their accumulated experience in patient care through reflective journaling. Thus, it is suggested that the use of reflective approaches is possible to measure the various affective domains among medical imaging students.

Drawing on the benefits of the concept of reflection and reflective learning discussed above, there is much to do by medical imaging educators. There are various teaching and assessing methodologies to represent the reflection needed. Future work will also involve the formulation of the assessment rubrics that would clearly show the applications of reflection in the chosen assessment methodology. The different characteristics of the domains within medical imaging education will be a major challenge in developing

(C) The Internet Journal of Allied Health Sciences and Practice, 2018 
those rubrics. It is postulated that those challenges can be contained by aligning the efforts to the concept of outcome-based education. Resorting to an "adapt or adopt" strategy to those successful approaches can facilitate the planning and implementation of using the concept of reflection in education, which could reduce the fatigue in formulation from beginning the concept of reflection into medical imaging education. Furthermore, those success stories can be used as indicators of success when applied to medical imaging education. However, it is to be reiterated that the specific characteristics of the domains in medical imaging education will require attention to be given the style, action verbs, and weightage of the assessment that will depict the reflection in terms of the integration of theory into practice. A holistic model based on the concept of outcome-based education can provide the guide towards the application of reflective approaches in medical imaging education.

\section{Conclusion}

This initial review based on Scopus database has demonstrated the current approaches based on the concept of reflection that were used to facilitate learning and assessment in various medical disciplines. It is important to note here that more studies are required to reduce the gap between medical imaging and other health professions toward the understanding of the concept of reflection in the education system. The broad definitions of the term reflection as evident in the literature can be used to relate the application of reflection within their individual contextual meanings and when indicated. The process of reflection involves several steps that ultimately are used to develop and promote the crucial mindedness and professionalism and facilitate the learning of the individuals. The uses of various reflective approaches that include reflective writing and reflective journaling have been associated with academic success of students and improving the domain of patient care. The development of the various models of reflective approaches is used to guide both students and lecturers in terms of introducing, understanding, and directing them towards the necessary steps and themes in order to achieve a successful undertaking.

This work demonstrates that adapting and adopting the lessons learned from the application of various reflective approaches in the other disciplines can be used to benefit the learning and assessment as well as enhancing interpersonal skills in medical imaging education. In another perspective, the dearth of literature related to medical imaging education should be observed in the avenues for medical imaging educators to develop robust studies that evaluate the efficacy of reflective approaches to the macroand micro-domains of medical imaging education. A positive interpretation of the above discussions is that the presented studies showed the utility of reflective approaches in addressing the areas under professionalism. These areas are similar in medical imaging education. It is anticipated that there will be many challenges and constrains in presenting the reflection concept in medical imaging curriculum. The challenges and constraints could be in relation to the educational framework adopted by the respective institutions, the concept of outcome-based education and reflective practice as a tool for assessing outcomes. These approaches should be explored further by the medical imaging educators

\section{REFERENCES:}

1. Grellier J, Fisher D, McKay J. Encouraging a Reflective Approach to Learning as a Means of Strengthening Academic and Work Place Earning. In Preparing for the Graduate of 2015. Proceedings of the 17th Annual Teaching Learning Forum, 30-31 January 2008. Perth: Curtin University of Technology. Available at: http://otl.curtin.edu.au/tlf/ttf2008/refereed/grellier.html. Accessed January 3, 2017.

2. Dewey J. How We Think. Boston: D. C. Heath \& Company. 1910. https://www.gutenberg.org/files/37423/37423h/37423-h.htm

3. Rodgers C. Defining reflection: Another look at John Dewey and reflective thinking. Teachers College Records. 2002;104(4):842-66.

4. $\quad$ Ferraro JM. Reflective Practice and Professional Development. ERIC Digest. 2000. Available at: http://files.eric.ed.gov/fulltext/ED449120.pdf. Accessed March 25, 2017.

5. McClure P. Reflection on Practice. Making practice- based learning work project, University of Ulster. 2005. Available at: http://cw.routledge.com/textbooks/9780415537902/data/learning/8_Reflection\%20in\%20Practice.pdf. Accessed March 1, 2017.

6. Ruland JP, Ahern NR. Transforming student perspectives through reflective writing. Nurse Educator. 2007;32(2):81-8.

7. Lambert J, Mitrani V. Four Steps Reflection Process. Tools for Learning School. 2013. Available at: http://www.literacyinlearningexchange.org/sites/default/files/four-step-reflection-process_lforward.pdf. Accessed January 27, 2017.

8. Primrose RA. The Eight Steps of Reflective Thinking. 2003. Available at: http://russprimrose.com/index.php/The_Eight_Steps_of_Reflective_Thinking. Accessed March 01, 2017.

9. Lew MDN, Schmidt HG. Self-reflection and academic performance: Is there a relationship? Adv Health Sci Edu. 2011;16(4):529-45. Available at http://doi.org/10.1007/s10459-011-9298-z. Accessed March 1, 2017

10. Chinniah K, Nalliah S. Reflective writing in case summary assignments. leJSME. 2012;6(1):15-20. Available at: http://web.imu.edu.my/ejournal/approved/4.Review_sNalliahChinniah_p15-20.pdf. Accesed March 1, 2017.

(C) The Internet Journal of Allied Health Sciences and Practice, 2018 
11. Wear D, Zarconi J, Garden R, Jones T. Reflection in/and writing: Pedagogy and practice in Medical education. Acad Med. 2012;87(5):603-9. [PMID: 22450174]

12. Malaysian Qualifications Agency. Guidelines to Good Practice: Assessment of Students, 2012. Available at: http://pesona.mmu.edu.my/ jhlow/OBE\%20Reference/ASSESEMENT\%20OF\%20STUDENT.pdf. Accessed March 1, 2017.

13. Zimmerman SS, Byram Hanson DJ, Stube JE, Jedlicka JS, Fox L, et al. Using the power of student reflection to enhance professional development. Internet J Allied Health Sciences and Prac. 2007;5(2). Available at: http://nsuworks.nova.edu/cgi/viewcontent.cgi?article=1146\&context=ijahsp. Accessed March 25, 2017.

14. Epstein RM. Assessment in medical education. J New Eng Med. 2007;356(4):387-96. Available at: http://doi.org/10.1056/NEJMra054784. Accessed March 1, 2017. [PMID: 17251535]

15. Shapiro J, Kasman D, Shafer A. Words and wards: A model of reflective writing and its uses in Medical education. J Med Humanity. 2006;27(4):231-44.

16. Mcquire L, Lay K, Peters J. Pedagogy of reflective writing in professional education. 2009;9(1):93-107.

17. Chen I, Forbes C. Reflective writing and its impact on emphaty in Medical education: Systematic review. J Edu Eval Health Prof. 2014;11(20). Available at: http://dx.doi.org/10.3352/jeehp.2014.11.20. Accessed March 1, 2017. [PMID: 25112448]

18. Zainuddin ZI. A thematic study of Islamic perspective in Scopus indexed articles. Implications on Medical imaging. Libr Philo Prac. 2015;Paper 1233.Available at: http://digitalcommons.unl.edu/cgi/viewcontent.cgi?article=3250\&context=libphilprac. Accessed March 26, 2017.

19. Hamilton J, Druva R. Fostering appropriate reflective learning in an undergraduate radiography course . Radiography. 2010;16(4):339-45. Available at: http://dx.doi.org/10.1016/j.radi.2010.03.005. Accessed March 2, 2017.

20. Mubuuke AG, Kiguli- Malwadde E, Kiguli S, Businge F. Student portfolio: The golden key to reflective, experiential, and evidence- based learning. J Med Imag Rad Sc. 2010;41(2) Available at: http://dx.doi.org/10.1016/j.jmir.2010.03.001. Accessed March 1, 2017.

21. Hall M, Davist M. Reflections on radiography. Radiography. 1999;5:165-72. Availaible at: http://dx.doi.org/10.1016/S1078-8174(99)90025-1. Accessed March 25, 2017.

22. Baird MA. Towards the development of a reflective radiographer: Challenges and constraints. J Biomed Imaging Interv. 2008;4(1). Available at:https://www.ncbi.nlm.nih.gov/pmc/articles/PMC3097707/. Accessed March 26, 2017. [PMID: 21614320]

23. Chelliah KK, Arumugam Z. Does reflective practice enhance clinical competency in Medical imaging undergraduates? Proc Soc Behav Sc. 2012;73-7. Availble at:http://ac.els-cdn.com/S1877042812038049/1-s2.0-S1877042812038049main.pdf? Accessed March 26, 2017.

24. Yuekming H, Manaf LA. Assessing learning outcomes through students' reflective thinking. Proc Soc Behav Sc. 2014;152:973- 977. Available at:http://doi.org/10.1016/j.sbspro.2014.09.352. Accessed March 1, 2017.

25. Queensland University of Technology. The 4Rs Model of Reflective Thinking. 2010. Available at: http://www.citewrite.qut.edu.au/write/4Rs-for-students-page1-v1.5.pdf. Accessed March 01, 2017.

26. Ludwig S. Domain of Competence: Professionalism. Acad Pead. 2014;14:66-9. Available at: https://www.acgme.org/Portals/0/PDFs/Milestones/ProfessionalismPediatrics.pdf. Accessed May 25, 2017.

27. Black PE, Plowright D. Exploring pharmacists' views about the contribution that reflective learning can make to the development of professional practice. Int J Pharm Prac. 2009;9(1):149-55.

28. Braun UK, Gill AC, Teal CR, Morrison LJ. The Utility of Reflective Writing after a Palliative Care Experience: Can We assesses Medical students' professionalism? J Pall Med. 2013;16(11):1342-9. Available at: https://doi.org/10.1089/jpm.2012.0462. Accessed May 25, 2017.

29. Kennison M. Developing reflective writing as effective pedagogy. J Nursing Educ Persp. 2012;27(5):306-11.

30. The University of Worcester. Study Skills Advice Sheets. Learning journal, 2016. Available at: http://www.worcester.ac.uk/studyskills/documents/Learning_Journals_2016.pdf. Accessed March 1, 2017.

31. Dye D. Enhancing critical reflection of students during clinical internship using the self- S.O.A.P. note. Internet J Allied Health Sciences Prac. 2006;3(4). Available at: http://nsuworks.nova.edu/cgi/viewcontent.cgi?article=1084\&context=ijahsp. Accessed March 25, 2017.

32. Kok J, Chabeli MM. Reflective Journal Writing: How it promotes reflective thinking in clinical nursing education: A students ' perspective. 2002;35-42. Available at: www.curationis.org.za/index.php/curationis/article/download/784/721. Accessed March 26, 2017.

33. Zori S. Teaching critical thinking using reflective journaling in a Nursing fellowship program. J Cont Educ Nursing. 2016;47(7). Available at: http://search.proquest.com/openview/f3a9824f86cb30d8e821249e70f8cbf3/1.pdf?pqorigsite=gscholar\&cbl=35533. Accessed March 25, 2017. 
34. Raterink G. Reflective journaling for critical thinking development in advance practice registered Nurse students. J Nursing Educ. 2016;55(2). Available at: DOI:10.3928/01484834-20160114-08. Accessed March 25, 2017. [PMID: 26814821]

35. Cottrell J. Reflective journals in clinical practice for radiation therapy students. J Radiother Prac. 2006;(5):9-16.

36. Lasater K, Nielsen A. Reflective journaling for clinical judgment development and evaluation. J Nursing Educ. 2009;48(1). Available at:https://www.researchgate.net/profile/Ann_Nielsen2/publication/24025679_Reflective_Journaling_for_Clinical_Judgm en t_Development_and_Evaluation/links/53d255450cf2a7fbb2e99552.pdf. Accessed March 26, 2017. [PMID: 19227755]

37. Findland N, Dempsey S, Forward HW. Validation and use of the Newcastle reflective analysis tool: A three- year longitunal study on Radiation therapy students. Reflective Practice. 2010;11(1). Available at: http://dx.doi.org/10.1016/j.jmir.2010.03.001. Accessed March 26, 2017.

38. Simpson E, Courtney MA. Framework guiding critical thinking through reflective journal documentation: A middle estern experience. J Int Nursing Prac. 2007;13(4). Available at: http://dx.doi.org/10.1016/j.jmir. Accessed March 26, 2017.

39. Bussard ME. Clinical judgment in reflective journals of prelicensure Nursing students. J Nursing Educ. 2015;54(1):40. [PMID: 25535760]

40. McMillan-Coddington D. Reflection through journal writing to educate registered Nursing students on patient care. J Teach Learning in Nursing. 2013;8(2). Available at: DOI: http://dx.doi.org/10.1016/j.teln.2012.09.004. Accessed March 1, 2017.

41. Boyd EM, Fales AW. Reflective learning: Key to learning from experience. J Humanistic Psychol Qgv. 1983;23(2):99117.

42. Sandars J, Murray C, Pellow A. Twelve tips for using digital storeytelling to promote reflective learning by Medical students. J Med Teach. 2008;30(8). Available at: DOI:10.1080/01421590801987370. Accessed March 9, 2017. [PMID: 18946821] 